\title{
A 3D Model for Building Condition Assessment
}

\author{
Anna Banaszek ${ }^{1}$, Sebastian Banaszek ${ }^{1}$, Anna Cellmer ${ }^{2}$, Vicenç Gibert $^{3}$ \\ and Carles Serrat ${ }^{4}$
}

\footnotetext{
${ }^{1}$ Training and Research Center “DroneTechCamp”, Ul. Jarocka 64/2, 10-699, Olsztyn, Poland, \{anna.banaszek, sebastian.banaszek\}@banaszekgroup.pl

${ }^{2}$ Dept. of Geoinformatics, The Faculty of Civil Engineering, Environmental Engineering and Geodesy, Koszalin University of Technology, Koszalin, Poland, anna.cellmer@tu.koszalin.pl

${ }^{3}$ LABEDI-EPSEB, Dept. of Architectural Technology, Universitat Politècnica de CatalunyaBarcelonaTECH, Av. Dr. Marañón, 44-50, 08028-Barcelona, Spain, vicenc.gibert@upc.edu

${ }^{4}$ IEMAE-EPSEB, Dept. of Mathematics, Universitat Politècnica de Catalunya-BarcelonaTECH, Av. Dr. Marañón, 44-50, 08028-Barcelona, Spain, carles.serrat@upc.edu
}

\begin{abstract}
The aim of the paper is to analyze practical aspects with use of $3 D$ Model for accurate building condition assessment. Use of fully interactive visualization methods from a technical condition assessment platform going to be, especially taking into consideration current COVID-19 scenarios, a very supportive tool for the massive inspection of building stocks, particularly in big residential areas. The authors present the approach based on high-performance images that were captured by Unmanned Aerial Vehicles (UAVS). The next step is the generation of a 3D model and orthophotos of building facades. The graphical information together with tables of attributes will allow the interactive georeferenced management and assessment, that is proposed as a form of interactive cooperation. The idea of this approach corresponds widely with the Building Information Modeling aims. The authors introduce the methodology, stages of the inventory and follow-up process carried out within the platform requirements together with advantages of the visualization techniques, basing on a particular case study. Technical details about the information system and the analysis connected with the visualization utility will be presented and illustrated.
\end{abstract}

Keywords: Technical Condition, Assets Assessment, UAV, BIM, GIS.

\section{Introduction}

The main aim of this paper is to introduce the further research and development of the utility previously presented by Banaszek et al. (2019) for the accurate assessment of the technical condition of buildings, as an efficient strategy and platform for the massive inspection of building stocks, in big residential areas. The approach is based on high-performance images captured by UAVs, and it is inspired by authors' previous works in the context of the Building Research Analysis and Information Network (Serrat et al., 2011, 2017).

The first successful ideas about using images taken from a model helicopter partly for the generation of a 3D-model of an historical mill we may find in Zischinsky et al. (2000). In recent years, there has been a growing demand in using UAVs for variety of purposes including monitoring, surveillance and information collection tasks. The application contexts and the objectives are different and diverse: natural disasters detection and monitoring, (Alexis et al., 2009, Neto et al., 2012, Popescu et al., 2015), marine-oceanic missions, (Rubio et al., 2004; Reineman et al., 2016; Schaub et al., 2018), surveillance of complex urban environments 
(Semsch et al. 2009) among others. The specific use of multiple UAVs for a persistent surveillance aim has been also considered, and studied with optimized algorithms in (Nigam et al., 2012). Even taking into consideration all mentioned applications and research, the use of UAVs for collecting accurate information in a building, with purpose to assess and monitor its technical condition, has not been enough established. Few seminal studies have been developed (Eschmann et al., 2012; Hallerman et al., 2015; Banaszek et al., 2017) and by Serrat et al. (2018, 2019).

The idea presented in the article includes the full interactive visualization method for building condition assessment platform and may be considered as a part of the broadly understood Building Information Modeling (BIM). As a real-time capturing of data technology, UAV is used in the construction industry. In the recent years, the UAVs have been successfully used for different construction and operation applications of various types of construction projects (Asnafi et al., 2018). The topic of adapting the UAV technologies to efficiently collect information for an efficient BIM update, building management and documentation is being studied and considered in terms of systematic use by various authors (Vacanas et al., 2015; Chen et al., 2019; Grosso et al., 2020).

The paper is organized as follows. In Section 2 it will be presented the main methodology. Section 3 contains description of the case study and details of the procedure illustrated by a) the resulting 3D and 2D models for the building under assessment, and b) pictures of the elements, damages and severities identified by the methodology as a result of the inspection.

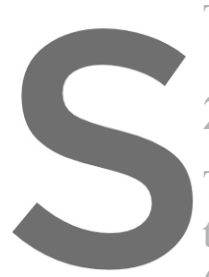
The paper ends with a

\section{Methodology}

The new technologies in UAV data acquisition
the method of visual buil ding inspection using (in-flight) and digital post-processing (post-flig ht)
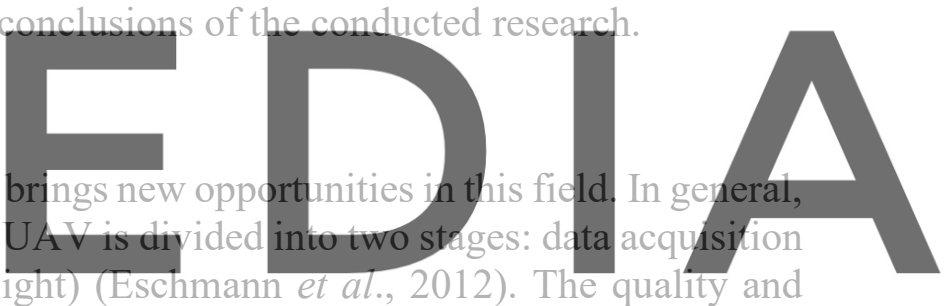
variety of data obtained from UAVs depends largely on installed sensors, the technical

been technically protocolized in order to get the proper high-quality information about the real condition of the building. Based on that, the following methodology of a Fully Interactive Visualization is established and studied for building condition assessment.

Various research results (Mesas-Carrascosa et al., 2014.) proved that the UAVs orthophotos satisfactorily passed the spatial quality tests. The tested areas include urban, flat, agricultural and woods lands. Lately research have proposed building damage detection algorithms which use remote sensing technology. To estimate building damage detection and urban structural damage methods using UAV images and using 3D models' various authors described their possibilities (Torok et al., 2014; Fernandez et al., 2015; Maliki et al., 2016) The results shows that geometric parameters derived from the $3 \mathrm{D}$ point cloud can reveal damage indicators that are difficult to detect in the original imagery.

\section{Case Study}

The building was selected after taking into account the visible technical wear of the facade, the complicated shape and roof, and its location in a dense urban surrounding. The flight plan was established separately for each of the six facades and one for the whole roof, out in total there 
were seven flights. The location in dense urban buildings required great caution during the flight. Usually during the flight there are variety of obstacles like the location of the sidewalks and the roadway next to the building caused the necessity of interrupting the flight when pedestrians or cars appeared, in particular the buses. Despite all these difficulties, the flight was carried out, which finally confirmed that the suggested solution can be used for the majority of buildings requiring a technical condition assessment.

For the experiment the DJI Inspire One lightweight quadcopter with the following specifications were used: weight: $2935 \mathrm{~g}$, vertical GPS accuracy: 0,5 m (accuracy determination), horizontal GPS accuracy: $2,5 \mathrm{~m}$ (accuracy of X, Y coordinates), Climb speed: $5 \mathrm{~m} / \mathrm{s}$, max. drop speed: $4 \mathrm{~m} \mathrm{~s}$, max. cruising speed: $22 \mathrm{~m} / \mathrm{s}$ (ATTI mode, no wind), maximum flight height: $4500 \mathrm{~m}$ ASL (Above Sea Level), max. wind force: $10 \mathrm{~m} / \mathrm{s}$, flight time: 18 minutes, operating temperature: $-10^{\circ}$ to $40^{\circ} \mathrm{C}$, size: $438 \times 451 \times 301 \mathrm{~mm}$. Digital camera (RGB sensor) has been used to obtain digital images with the following specifications: $12 \mathrm{Mpix}$ resolution (4000x3000), physical size $6.170 \mathrm{~mm} \times 4.628 \mathrm{~mm}$, focal length: $3.55 \mathrm{~mm}$. The flight weather condition was high humidity and transient slight rainfall, the temperature was about +5 degrees, wind at about $5 \mathrm{~m} / \mathrm{s}$ (in gusts up to $10 \mathrm{~m} / \mathrm{s}$ ). As can be seen in Figure 1, despite the difficult weather conditions, vertical flight lines, including the assumed longitudinal and transverse overlap, have been preserved.

\subsection{Digital Processing, Orthophoto Plans Generation and 3D Model}

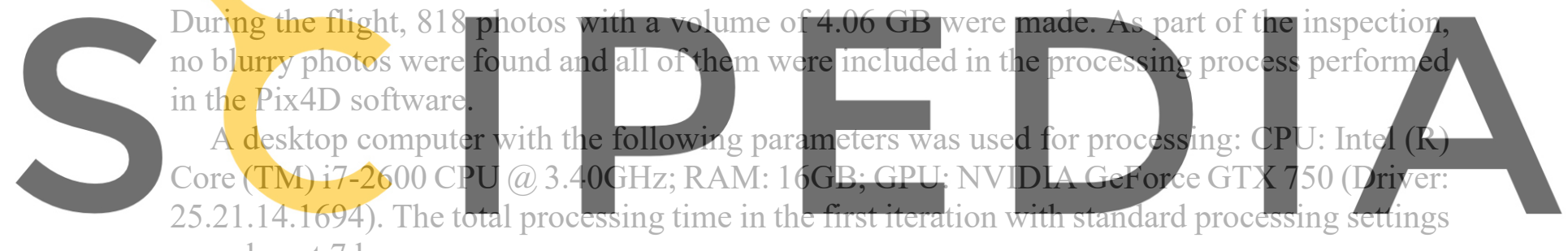

was almost 7 hours

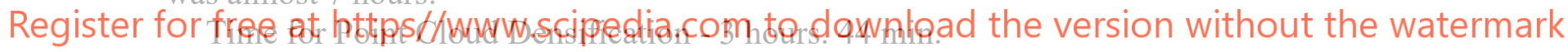

Time for 3D Textured Mesh Generation - 28 min.

Time for DSMGeneration - 42 min.

Time for Orthomosaic Generation - 1 hour. 42 min.

The following results of processing have been achieved:

GSD at the level of $0.36 \mathrm{~cm} / \mathrm{pix}$.

817 out of 817 images calibrated (100\%), 1 image disabled.

$1.93 \%$ relative difference between initial and optimized internal camera parameters.

Median of 13924.4 matches per calibrated image.

At this stage, it can be confirmed that the coating, despite the difficulties, was made correctly and the material can be used to generate the facade and roof elevation for the purpose of assessing the technical condition of the building. The final effect in the form of a 3D model generated in the 3rd iteration after cleaning the point cloud and recalculating the design is shown in Figure 2. 


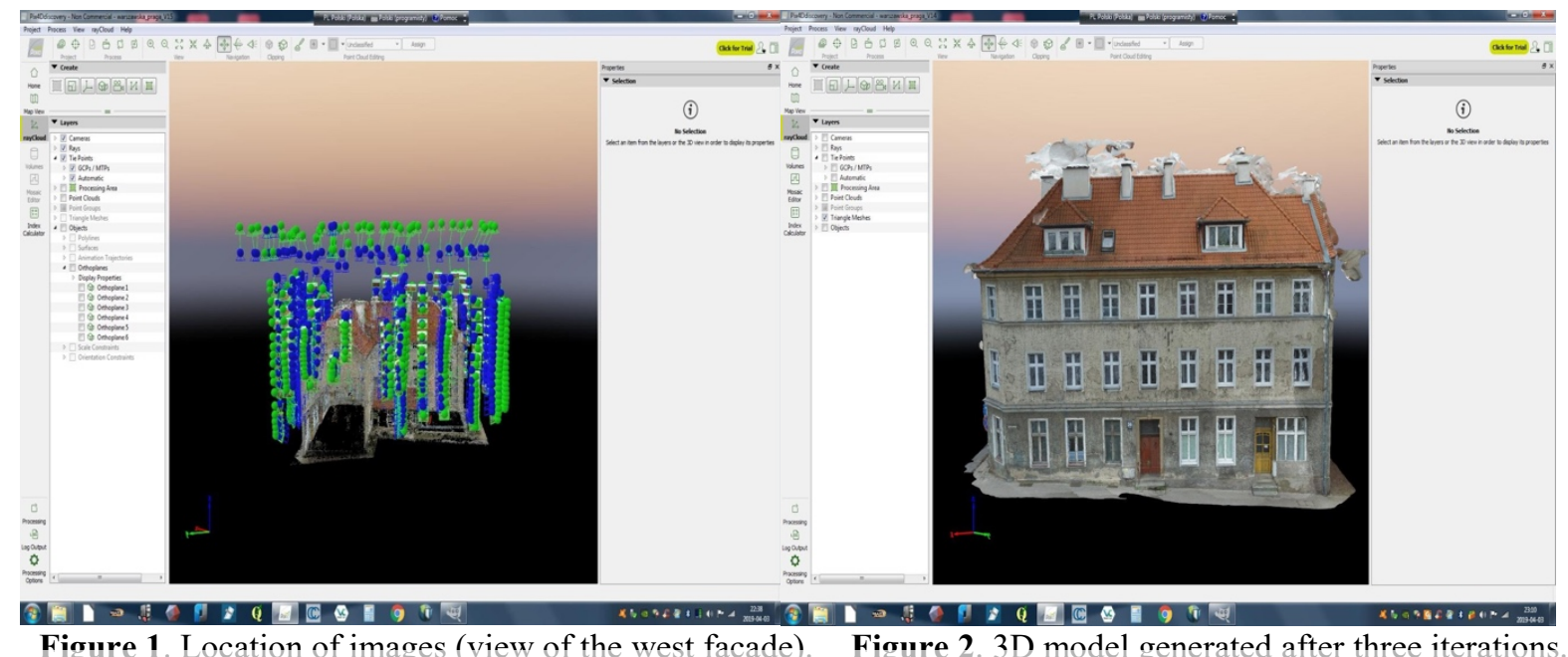

Because of the GPS signal disturbances occurring during the raid, the data was processed in two blocks. Block I included the following elevations: south-west, west, north-west, north-east and a roof, and Block II included the south-eastern elevation.

On the one hand, it was necessary to enter the 11 manual tie point and reprocess the data to align the blocks. As a result, the cloud was generated in one block, and the inventoried object was characterized by the correct geometry, shape and proportions. Finally, the relative camera position and orientation of the uncertainties X, Y and Z was obtained at $<0.025$ for $<0.015$ for sigma. On the other hand, it was also convenient to carry out manual cl classification of the point cloud to generate a 3D model devoid of artifacts. (Figure 3 4). This was long 6 hours process, but it resulted in the generation of a model prac from contamination. The modd allows it to be used for the visualization of selected, inventoried phenomena in 3D space in a natural way for the user. The carried-out process of cleaning the

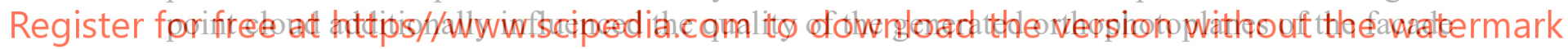
and roof. In this stage, for each of the elevations an orthophotoplan separation was generated.

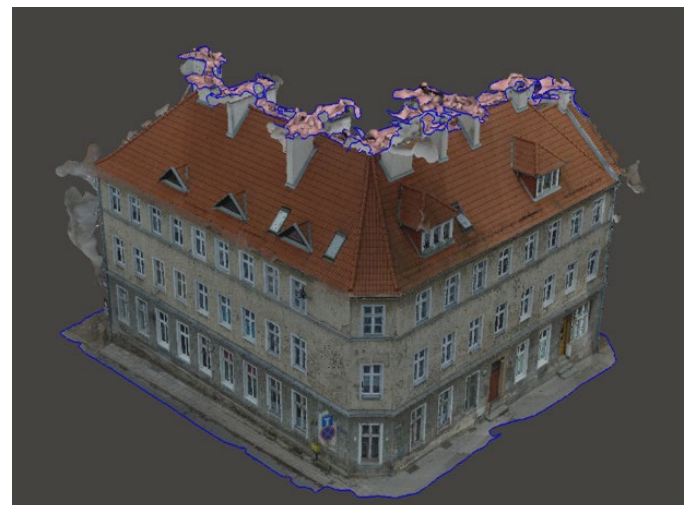

Figure 3. Visualization of the generated model in $3 \mathrm{D}$ space.

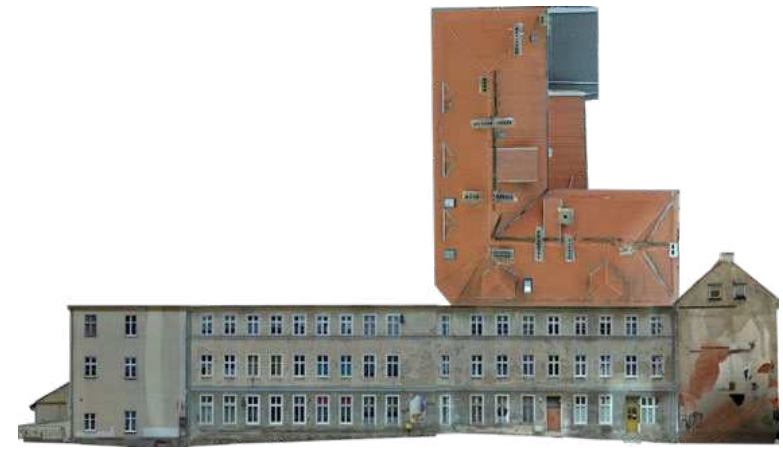

Figure 4. 3D model of an inventoried building in a flat projection. 


\subsection{A Square Grid and the Classification of Building Elements}

In order to additionally view the selected image directly from the GIS application by indicating its center, the above-mentioned data should be enriched with the path to the directory in which the images will be ultimately stored. Good option for it is to use batch directory inventory software that saves data most often in a .txt file. Today's spreadsheets give us possibilities that can easily combine the contents of both files and generate a .txt or .csv file with the appropriate structure. The files prepared in such manner which are imported into the GIS software, after indicating columns containing the selected coordinates, enables visualization of image centers and preview of images directly from the application without the need to know their physical location. In case of image visualization in the orthophotomap area, we use the $\mathrm{X}$ and $\mathrm{Y}$ coordinates, in the case of orthophotos of elevations vertical $\mathrm{Z}$ and Y. During the. experiment it was generated a file consisting of 926 records, containing 5,556 attribute values. The next step to assign specific values of selected attributes for a previously defined part of the facade is to create a matrix of squares with an appropriate size. In our case study $40 \mathrm{~cm}$ was chosen as a convenient.

The most required elements of the facade that are classified in the manual process include, parts of the geometry of the facade and the roof, window and the door joinery and architectural details. In further research with various assumed accuracy of the final inventory of all basic elements of the building one can be subjected to classic polygon vectorization (for the most accurate inventories) or indicated by assigning individual mesh squares a value corresponding

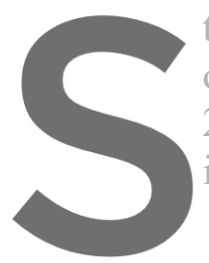
to the inventoried eleme of this experiment, we used the s 2 - molding, 3 - window, 4 identification of the elements.
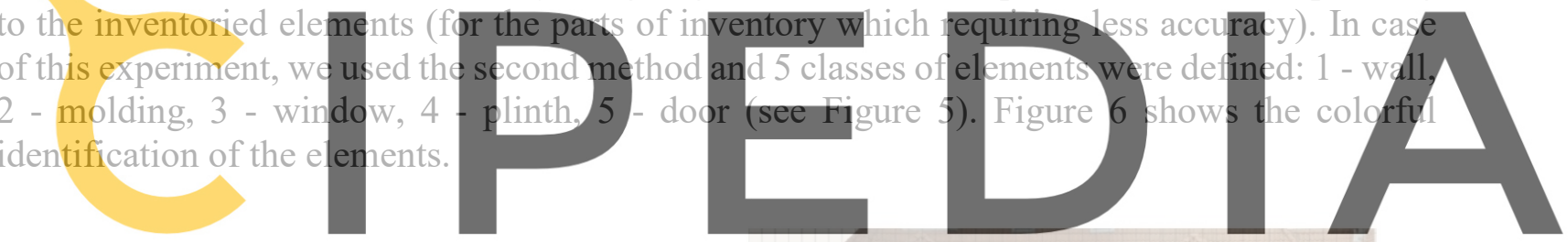

Register for free at https//www.scipedia.com to download the version without the watermark

\begin{tabular}{|c|c|c|}
\hline \multicolumn{2}{|l|}{ Etykieta } & Reguła \\
\hline$\checkmark$ & Fasade & "Fasade" = 1 \\
\hline$\checkmark$ & Wall & "Wall" = 1 \\
\hline$\checkmark$ & Door & "_Door" = 5 \\
\hline$\checkmark$ & Window & "Window" = 3 \\
\hline$\checkmark$ & Plinth & "_Plinth" = 4 \\
\hline$\checkmark$ & Molding & "_Molding" = 2 \\
\hline
\end{tabular}

Figure 7. List of classes of identified facade elements.

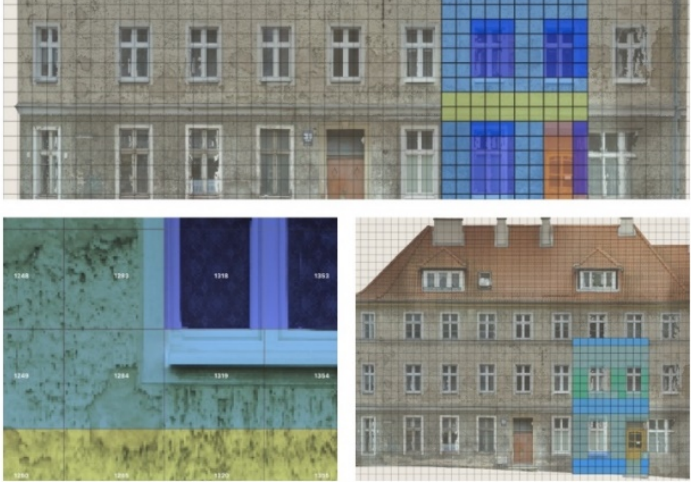

Figure 6. Ortophotoplan with completed qualification of inventoried elements. 


\subsection{The Visual Inventory of the Building}

In the last stage, inspector carries out a visual assessment of the technical condition of the facade and determines the degree and type of damage on the basis of orthophotoplanes, looking at the square grid and classification table. Such implementation enables the automatic visualization of the technical condition in accordance with the indicated criteria and the determination of the area and position of each type of defects in the asset under inspection (Figure 7).

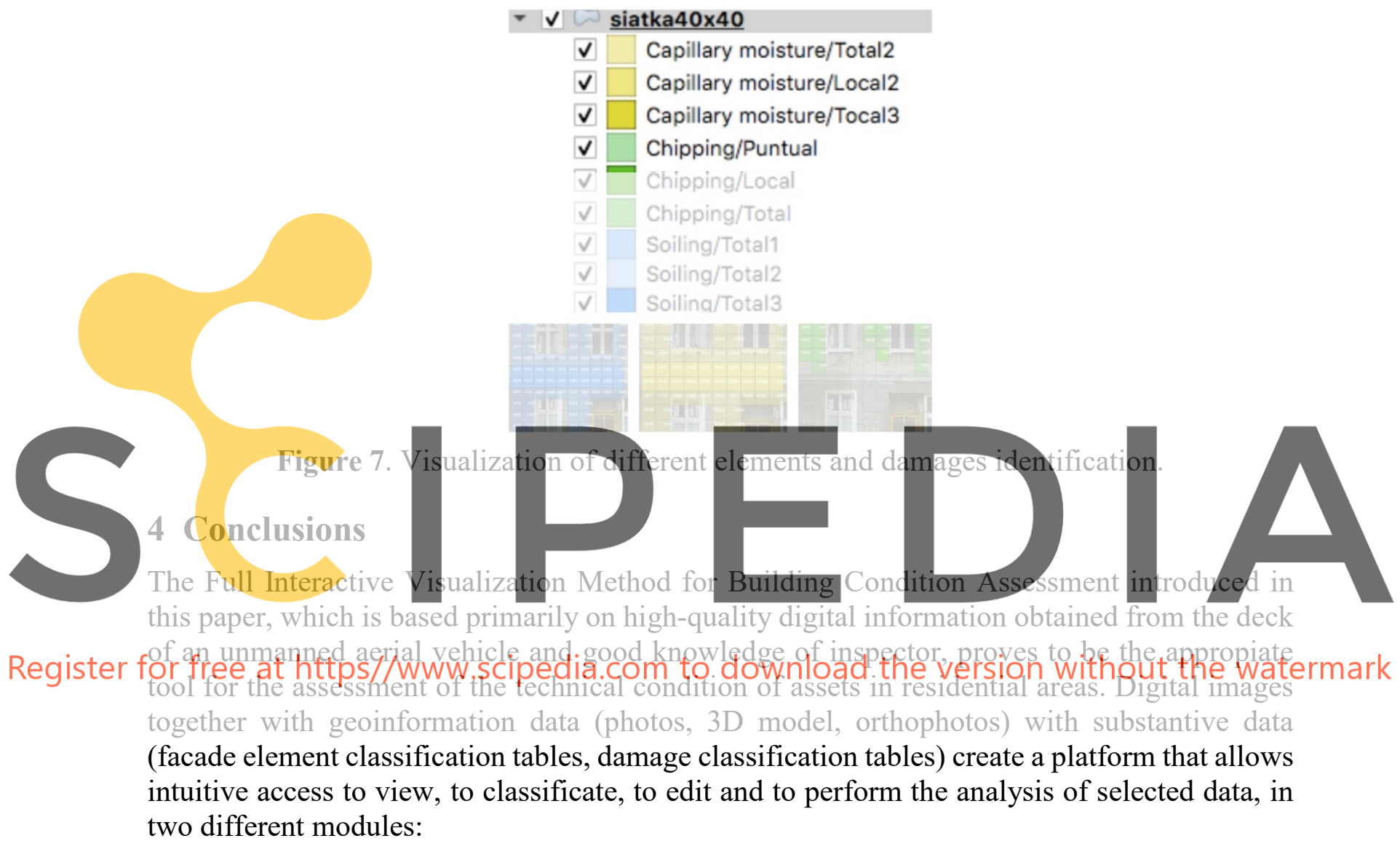

- The 3D module enables the visualization of selected inventoried elements or characteristics of the asset under inspection in a 3D space in a natural way for the user and is most often used to carry out inspections and move around the model.

- The 2D module allows the technician to visualize selected inventoried elements or characteristics of the asset under inspection in a 2D space in a way that enables a more accurate and reliable identification, location, measurement and assessment.

The proposed platform provides to the users with a modern and efficient utility enabling full integration of the construction inventory process with BIM. In times when it is becoming difficult to arrange all work in a traditional form, due to the COVID-19 pandemic constraints, this tool optimizes the tasks of the different working groups. A proposal that makes feasible the situation in which the inspector's work can be efficiently carried out completely online. 


\section{Acknowledgements}

This research has been partially supported by grants MTM2015-64465-C2-1-R (MINECO / FEDER) from the Ministerio de Economía y Competitividad (Spain) and 2017 SGR 622 from the Departament d'Economia i Coneixement de la Generalitat de Catalunya. Authors are grateful to the Laboratory of Photogrammetry and Remote Sensing (LFiT) Dron House S. A., Warsaw (Poland) its contribution in the technical part of using UAV technologies, as well as, to members of the IEMAE, LABEDI and GRASS-GRBIO groups their valuable comments and suggestions in the development of the work.

\section{ORCID}

Anna Banaszek: http://orcid.org/0000-0002-2744-2023

Sebastian Banaszek: http://orcid.org/0000-0001-6470-6270

Anna Cellmer: http://orcid.org/0000-0002-7872-6325

Vicenç Gibert: http://orcid.org/0000-0001-6341-5762

Carles Serrat: http://orcid.org/0000-0002-1504-5354

References

Alexis, K., Nikolakopoulos, G., Tzes, A. and Dritsas, L. (2009). Coordination of Helicopter UAVs for Aerial Forest-Fire Surveillance, in Valavanis K.P. (eds) Applications of Intelligent Control to Engineering Systems. Intelligent Systems, Control, and Automation: Science and Engineering, 39, 169-193, Springer, Dordrecht.

Asnafi, M. and Dastgheibifard, S. (2018). A Review on Potential Applications of Unmanned Aerial Vehicle for Construction Industry. Sustainable Structures and Materials, An International Journal, 1(2), 44-53.

Banaszek, A., Banaszek, S. and Cellmer, A. (2017) Possibilities of Use of UAVS for Technical Inspection of Buildings and Constructions. IOP Conference Series: Earth and Environment Science, 95, 032001, 1-6.

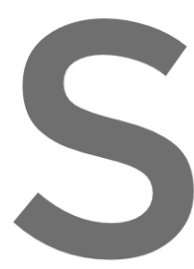

Banaszek, A., Banaszek, Method for Building

Chen, Y., Zhang, J. and Conference, 1-7.

Eschmann, C., Kuo, C.-M., Inspection and Monitoring, 6th European Worksho

Fernandez Galarreta, J., Kerle, N. and Gerke, M. (2015
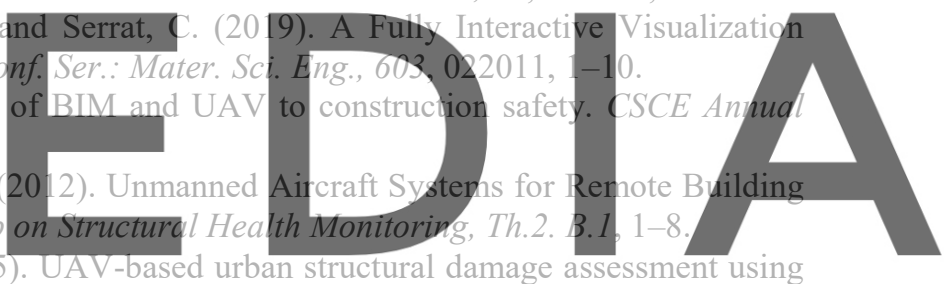
object-based image analysis and semantic reasoning. Nat. Hazards Earth Syst. Sci., 15, 1087-1101.

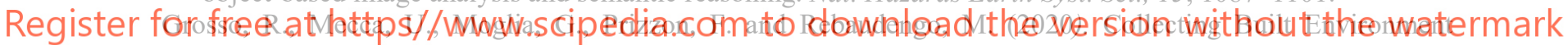
Information Using UAVs: Time and Applicability in Building Inspection Activities. Sustainability, 12(11), 115 .

Hallermann, N., Morgenthal, G. and Rodehorst, V. (2015). Unmanned Aerial Systems (UAS) - Case Studies of Vision Based Monitoring of Ageing Structures, International Symposium Non-Destructive Testing in Civil Engineering (NDT-CE), Berlin, Germany.

Malihi, S., Valadan Zoej, M.J., Hahn, M., Mokhtarzade, M. and Arefi, H. (2016). 3D Building Reconstruction Using Dense Photogrammetric Point Cloud. The International Archives of the Photogrammetry, Remote Sensing and Spatial Information Sciences, Volume XLI-B3, 71-74.

Mesas-Carrascosa, F.J., Rumbao, I.C., Berrocal, J.A.B. and Porras, A.G.-F. (2014). Positional Quality Assessment of Orthophotos Obtained from Sensors Onboard Multi-Rotor UAV Platforms. Sensors, 14, 22394-22407.

Neto, J.M.M., da Paixo, R.A., Rodrigues, L.R.L., Moreira, E.M., dos Santos, J.C.J. and Rosa, P.F.F. (2012). A surveillance task for a UAV in a natural disaster scenario, in 2012 IEEE International Symposium on Industrial Electronics, 1516-1522.

Nigam, N., Bieniawski, S., Kroo, I. and Vian, J. (2012). Control of Multiple UAVs for Persistent Surveillance: Algorithm and Flight Test Results, IEEE Transactions on Control Systems Technology, 20(5), 1236-1251.

Popescu, D., Ichim, L. and Caramihale, T. (2015). Flood areas detection based on UAV surveillance system. In 19th International Conference on System Theory, Control and Computing (ICSTCC), 753-758.

Reineman, B.D., Lenain, L. and Melville, W.K., (2016). The use of ship-launched fixed-wing UAVs for measuring the marine atmospheric boundary layer and ocean surface processes, Journal of Atmospheric and Oceanic Technology, 33(9), 2029-2052. 
Rubio, J.C., Vagners, J. and Rysdyk, R. (2004). Adaptive path planning for autonomous UAV oceanic search missions. In American Institute of Aeronautics and Astronautics 1st Intelligent Systems Technical Conference, $6228,1-10$.

Schaub, J., Hunt, B.P., Pakhomov, E.A., Holmes, K., Lu, Y. and Quayle, L. (2018). Using unmanned aerial vehicles (UAVs) to measure jellyfish aggregations. Marine Ecology Progress Series, 591, 29-36.

Semsch, E., Jakob, M. Pavlicek, D. and Pechoucek, M. (2009.) Autonomous UAV Surveillance in Complex Urban Environments. In 2009 IEEE/WIC/ACM International Joint Conference on Web Intelligence and Intelligent Agent Technology, 2, 82-85

Serrat, C., Banaszek, A., Cellmer, A and Gibert, V, (2019). Use of UAVs for Technical Inspection of Buildings Within the BRAIN Massive Inspection Platform, IOP Conference Series: Materials Science and Engineering, 471, 022008, 1-9.

Serrat, C., Cellmer, A., Banaszek, A. and Gibert, V. (2019) Exploring Conditions and Usefulness of UAVs in the BRAIN Massive Inspections Protocol. Open Engineering, 9, 1-6.

Serrat, C. and Gibert, V. (2011). Survival analysis methodology for service live prediction and building maintenance. In 12th International Conference on Durability of Building Materials and Components, Porto, Portugal, vol. II, 599-606.

Serrat, C., Gibert, V. Casas, J.R. and Rapinski, J. (2017). BRAIN: Building Research Analysis and Information Network. In XIV International Conference on Durability of Building Materials and Components, Ghent, Belgium, 325, 1-11.

Serrat, C., Gibert, V., Cellmer, A. and Banaszek, A. (2018). Quantitative comparison between visual UAV-based inspections for the assessment of the technical condition of building facades. In Research and modelling in civil engineering, J. Katzer, K. Cichocki and J. Domski (Eds), Koszalin University of Technology, 19-29.

Torok, M.M., Golparvar-Fard, M. and Kochersberger, K.B. (2014). Image-based automated 3D crack detection for post-disaster building assessment. Journal of Computing in Civil Engineering, 28(5).

Vacanas, Y., Themistocleous, K., Agapiou, A. and Hadjimitsis, D. (2015). Building Information Modelling (BIM)
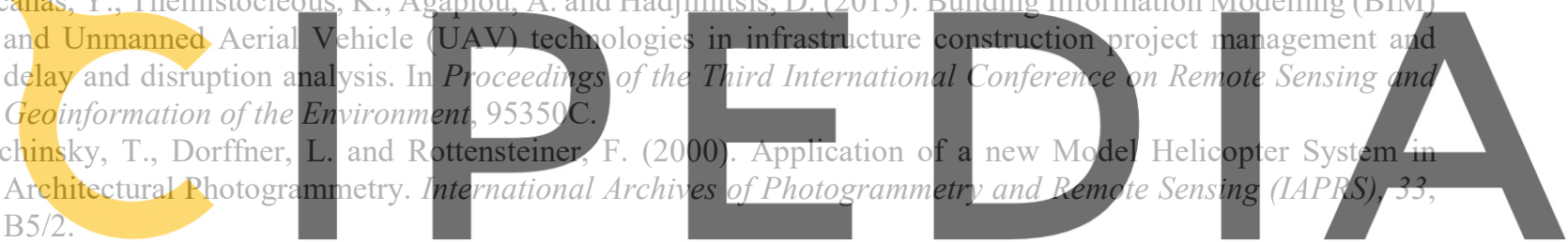

Register for free at https//www.scipedia.com to download the version without the watermark 